\title{
Impact of elevated maternal HIV viral load at delivery on T-cell populations in HIV exposed uninfected infants in Mozambique
}

Nilsa de Deus ${ }^{1,2+}$, Cinta Moraleda ${ }^{2,3+}$, Celia Serna-Bolea ${ }^{3}$, Montse Renom ${ }^{2,3}$, Clara Menendez ${ }^{2,3}$ and Denise Naniche ${ }^{2,3^{*}}$

\begin{abstract}
Background: HIV-uninfected infants born to HIV-infected mothers (HIV-exposed uninfected, HEU) have been described to have immune alterations as compared to unexposed infants. This study sought to characterize T-cell populations after birth in HEU infants and unexposed infants living in a semirural area in southern Mozambique.

Methods: Between August 2008 and June 2009 mother-infant pairs were enrolled at the Manhiça District Hospital at delivery into a prospective observational analysis of immunological and health outcomes in HEU infants. Infants were invited to return at one month of age for a clinical examination, HIV DNA-PCR, and immunophenotypic analyses. The primary analysis sought to assess immunological differences between HEU and unexposed groups, whereas the secondary analysis assessed the impact of maternal HIV RNA viral load in the HEU group. Infants who had a positive HIV DNA-PCR test were not included in the analysis.

Results: At one month of age, the $74 \mathrm{HEU}$ and the 56 unexposed infants had similar median levels of naive, memory and activated CD8 and CD4 T-cells. Infant naïve and activated CD8 T-cells were found to be associated with maternal HIV-RNA load at delivery. HEU infants born to women with HIV-RNA loads above $5 \log _{10} \mathrm{copies} / \mathrm{mL}$ had lower median levels of naïve CD8 T-cells $(p=0.04)$, and higher median levels of memory CD8 T-cells, $(p=0.014)$.

Conclusions: This study suggests that exposure to elevated maternal HIV-RNA puts the infant at higher risk of having early T-cell abnormalities. Improving prophylaxis of mother to child HIV programs such that more women have undetectable viral load is crucial to decrease vertical transmission of HIV, but may also be important to reduce the consequences of HIV virus exposure in HEU infants.
\end{abstract}

Keywords: HIV-exposed uninfected, T-cell, Naïve, Memory, Maternal HIV-RNA load, Africa

\section{Background}

Mother to child transmission (MTCT) of HIV occurs at a rate of $15 \%$ to $40 \%$ in a breastfeeding population in the absence of prevention measures [1]. However, prevention of MTCT of HIV (pMTCT-HIV) through antiretroviral prophylaxis, cesarean deliveries and formula feeding has successfully reduced MTCT to less than $1 \%$ in resource-rich countries [2-4]. In Sub-Saharan African countries, the last decade has witnessed a major rollout of pMTCT-HIV programs, which has contributed to

\footnotetext{
* Correspondence: dsuzanne@clinic.ub.es

${ }^{\dagger}$ Equal contributors

${ }^{2}$ Manhiça Health Research Centre (CISM), Manhiça, Mozambique

${ }^{3}$ Barcelona Centre for International Health Research (CRESIB), Hospital Clinic,

Universitat de Barcelona, C/Rossello 132, 4, Barcelona, Spain

Full list of author information is available at the end of the article
}

dropping rates of vertical transmission of HIV. However, with antenatal clinic HIV prevalence reaching 30\% in some countries [5,6], many infants are potentially exposed to HIV, although remaining uninfected. These HIV-exposed uninfected (HEU) infants may have immunological alterations which could lead to weakened responses to infections and vaccines and vulnerability to disease [7].

There is clear evidence that HEU infants present cytopenias including neutropenia as well as imbalances in levels of total CD4 and CD8 T-cells [8-20]. There is also increasing evidence that other immune abnormalities may be present in HEU infants, albeit to differing degrees, such as, altered cytokine production or memory/ naïve T-cell skewing [10,11,13-15,21-24]. The duration 
of these abnormalities is not clear. HEU infants may also have lower thymus output and increased immune activation as compared to unexposed infants $[9,14,21]$. However, reduced thymic size in HEU was not found to lead to differences in $\mathrm{T}$ cell phenotypes or function between HEU and unexposed infants at 15 months of age [25]. Some studies have suggested an important role of maternal and infant antiretroviral exposure in triggering immunological alterations, but the impact remains unclear $[22,26]$. HEU studies on lymphocytes and thymus output have mainly been conducted in Europe, North America and Brazil. The situation may be more complex in Sub-Saharan Africa [19] where independently of HIV, Africans have been shown to have lower levels of CD4, naïve T-cells and increased levels of activated T-cells as compared to Europeans [27-31]. In addition, environmental and setting-specific factors affecting immunological indicators may vary widely in Sub-Saharan Africa. For example, in areas of high malaria endemicity such as Mozambique, cord blood lymphocytes from mothers infected with malaria are often primed to parasite antigens and exhibit higher level of activation [32,33].

The clinical consequences of immune alterations observed in HEU infants are unknown. There has been an observation that HEU infants may mount a weaker immune response to BCG than infants born to HIVuninfected women $[34,35]$. Another consequence of impaired immunity could be that the severity, frequency and mortality associated with infections is exacerbated in HEU infants as compared to unexposed infants [36-39]; however it is not clear whether this is due to specific immune alterations [40-43] or to other mechanisms.

This study sought to characterize T-cell populations after birth in HEU infants and unexposed infants living in a semirural area in southern Mozambique where HIV clade $\mathrm{C}$ is the predominant circulating virus.

\section{Methods}

\section{Study population}

This study was conducted from August 2008 to August 2010 at the Manhiça District Hospital in southern Mozambique. The present study is integrated into a prospective observational analysis of immunological and health outcomes in infants born to HIV-infected mothers which has been described elsewhere [20]. National guidelines for pMTCT-HIV during the study followed the 2006 World Health Organization (WHO) recommendation [44]. At the time of the study, Highly Active Antiretroviral Therapy (HAART) was indicated for women in WHO disease stage 3 or 4 or $\mathrm{CD} 4<250$ counts $/ \mu \mathrm{l}$. For infants whose mothers received a complete pMTCT-HIV was based on a single dose of nevirapine (NVP) and daily zidovudine (AZT) during 1 week post-delivery and for those whose mothers did not receive a complete prophylaxis a single dose of NVP and 4 weeks of daily AZT was recommended. After the first month of the study, the pMTCTHIV national recommendation for children changed, and 4 weeks of daily AZT was recommended for all infants born to HIV-infected mothers. pMTCT-HIV was considered complete for the mother if she had received all treatments according to the guidelines, and for the newborn if he/she had received one dose of nevirapine in the first 72 hours after birth plus daily zidovudine for 4 weeks after delivery [44]. Women were counselled to exclusively breastfeed through 6 months. All HIV-infected mothers and HIV-infected infants were referred to the day hospital for clinical management according to national guidelines.

All participating mothers gave written informed consent, and the study protocol was approved by the Mozambican National Bioethics and the Hospital Clinic of Barcelona Ethics Review Committees.

\section{Study procedures}

At enrolment HIV serology testing was performed in the mothers using the Determine HIV-1/2 Rapid Test (Abbott Laboratories, Abbott Park, IL) and positive results were confirmed by the Uni-Gold Rapid Test (Trinity Biotech Co., Wicklow, Ireland) according to national guidelines. A $5 \mathrm{~mL}$ venous sample was drawn from HIV-positive mothers for CD4 cell counts and viral load determinations. Infants were invited to return at one month of age for a clinical examination, HIV DNAPCR, and blood drawing. Infants who had a positive HIV DNA-PCR test were not included in the analysis. Due to the difficult blood extraction, several children did not have enough blood for all the determinations. Only the children with all the parameters available were included in this analysis. The mother-infant pairs included: 1) HIV-infected mothers and their HEU infants and 2) HIV-uninfected mothers and their unexposed infants.

\section{HIV serological and virological determinations}

Infants were tested for HIV-1 using the Amplicor DNAPCR kit (Roche Diagnostics, Basel, Switzerland). HIVRNA quantification was performed from cryopreserved plasma samples with the commercial Roche Amplicor Monitor, version 1.5 (Roche Diagnostics, Basel, Switzerland). The assay had a lower limit of detection of 400 HIV-1 RNA copies $/ \mathrm{mL}$. For the purpose of analyses, plasma HIV-1 RNA concentrations below the limit of detection were assigned the value of 200 copies $/ \mathrm{mL}$.

\section{Immunophenotypic analysis}

CD4 and CD8 counting was performed from fresh whole blood after staining with labelled antibodies: CD4, CD3, CD8, and CD45 in TruCount tubes (Becton Dickinson Biosciences, California, USA). Samples were assessed by flow cytometry on a FACS Calibur (Becton Dickinson). 
Analysis was completed using Multiset software (Becton Dickinson Biosciences, California, USA).

To assess the percentage of activated CD4 and CD8 T lymphocytes, cell staining was performed with CD3, CD4 or CD8, CD38, and HLA-DR antibodies. Activated T-cells were defined as those CD4 or CD8 T-cells expressing both CD38 and HLA-DR surface markers. The percentage of naïve CD4 and CD8 was determined with CD62L and CD45RA antibodies whereas the percentage of memory CD4 and CD8 T-cells was evaluated by panCD45RO antibody staining.

\section{Statistical analysis and definitions}

HEU infants were defined as those having a negative HIVDNA PCR test at 1 month of age. Parity was categorized as primiparous if this was the first pregnancy and multiparous if the mother had had any previous pregnancy. Low birth weight was defined as birth weight $<2500$ grams.

Comparisons between groups for proportions were assessed using the chi-square test or Fisher's exact test where appropriate. For the T-cell population studies, analyses were made on continuous variables. The KruskalWallis test was used to compare independent continuous variables between groups. The Wilcoxon signed rank test was used for analysis of paired data. The Spearman correlation was used to assess correlations between nonnormally distributed continuous variables.

Statistical analysis was performed using STATA version 12.0 (StataCorp, College Station, TX). The primary analysis sought to assess immunological differences between HEU and unexposed groups, whereas the secondary analysis assessed the impact of the maternal HIV RNA viral load within the HEU group.

\section{Results}

\section{Study population}

Between August 2008 and June 2009, 318 mothers, 158 HIV-infected women and 160 HIV-uninfected women were enrolled at the Manhiça District Hospital [20]. Of these, $110 \mathrm{HIV}$-infected and $75 \mathrm{HIV}$-uninfected women came to the clinic at the infant's one month visit and were included in this study. Ten infants were determined to be HIV-infected at 1 month of age and excluded from the analysis. Of the remaining 175 mother-infant pairs, 130 infants had all immunological measures at 1 month of age, (74 infants born to HIVinfected mothers and 56 infants born to HIV-uninfected mothers). The 45 mother-infant pairs lost to follow up were comparable to the 130 used in this analysis in terms of demographic characteristics (data not shown).

Demographic and clinical characteristics of mothers and their infants at delivery were comparable between HEU and unexposed groups (Table 1). The 130 mother-infant pairs included in this analysis were comparable to the overall study population in terms of parity, age and birth weight and for HIV-infected women in terms of CD4 counts and HIV RNA levels (data not shown) [20]. At delivery the median maternal CD4 T-cell counts of HIV-infected mothers was 624 cells/ $\mu \mathrm{l}$ (IQR: $495-837$ ) and $17 \%$ of the women had levels

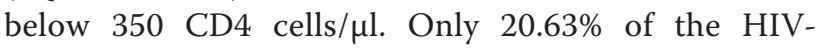
infected women had undetectable HIV RNA at delivery and median HIV RNA load was $3.91 \log _{10}$ copies $/ \mathrm{mL}$ (IQR: 2.97-4.67). Eighty-two percent of HIV-infected mothers received complete pMTCT-HIV. At onemonth of age, close to $90 \%$ of infants were receiving exclusive breastfeeding.

Table 1 Demographic and clinical characteristics of mothers and their infants at delivery according to maternal HIV serostatus $(n=130)$

\begin{tabular}{|c|c|c|c|c|c|}
\hline & \multicolumn{2}{|c|}{ HIV-infected } & \multicolumn{2}{|c|}{ HIV-uninfected } & \multirow[t]{2}{*}{$\mathbf{P}$} \\
\hline & $N=$ & & $N=$ & & \\
\hline \multicolumn{6}{|l|}{ Parity (n, \%) } \\
\hline primigravidae & 14 & 18.92 & 11 & 19.64 & 0.917 \\
\hline multigravidae & 60 & 81.08 & 45 & 80.36 & \\
\hline Age (yrs) [median (IQR)] & & $25(22-30)$ & & $23(20-31)$ & 0.335 \\
\hline Low Birth weight, $(n, \%)$ & 3 & 4.17 & 1 & 1.82 & 0.453 \\
\hline Birth weight (gr) [median (IQR)] & & $3000(2800-3300)$ & & $3100(2900-3350)$ & 0.253 \\
\hline \multicolumn{6}{|l|}{ Sex, $(n, \%)$} \\
\hline male & 42 & 56.76 & 23 & 41.07 & 0.077 \\
\hline female & 32 & 43.24 & 33 & 58.03 & \\
\hline Maternal HIV RNA $\log _{10}{ }^{*}$ (copies/mL) [median (IQR)] & & $3.91(2.97-4.67)$ & & NA & \\
\hline Maternal CD4 counts (cells/Ml) [median (IQR)] & & $624(495-837)$ & & NA & \\
\hline
\end{tabular}




\section{Distribution of T-cell populations among HEU and unexposed infants at 1 month of age}

To investigate the impact of maternal HIV infection on the distribution of infant T-cells subsets, percent activated, naïve and memory CD4 and CD8 T-cell subsets were assessed in HEU and UE infants.

At one month of age, the seventy-four HEU and the fifty-six unexposed infants had similar median levels of naive, memory and activated CD8 and CD4 T-cells (Figure 1).

\section{The impact of maternal HIV viral load on levels of naïve and memory CD8 T-cells}

Within HEU infants, levels of naïve CD8 T-cells showed a significant negative association with maternal HIV RNA viral load (Spearman correlation: rho $=-0.324$, $\mathrm{p}=0.016$ ) whereas levels of naïve CD4 T-cells were not significantly associated with maternal HIV RNA (Figure 2). Memory CD8 T-cells and activated CD8 T-cells were positively associated with maternal HIV RNA viral load (memory: Spearman rho $=0.293 \mathrm{p}=0.031$ and activated:
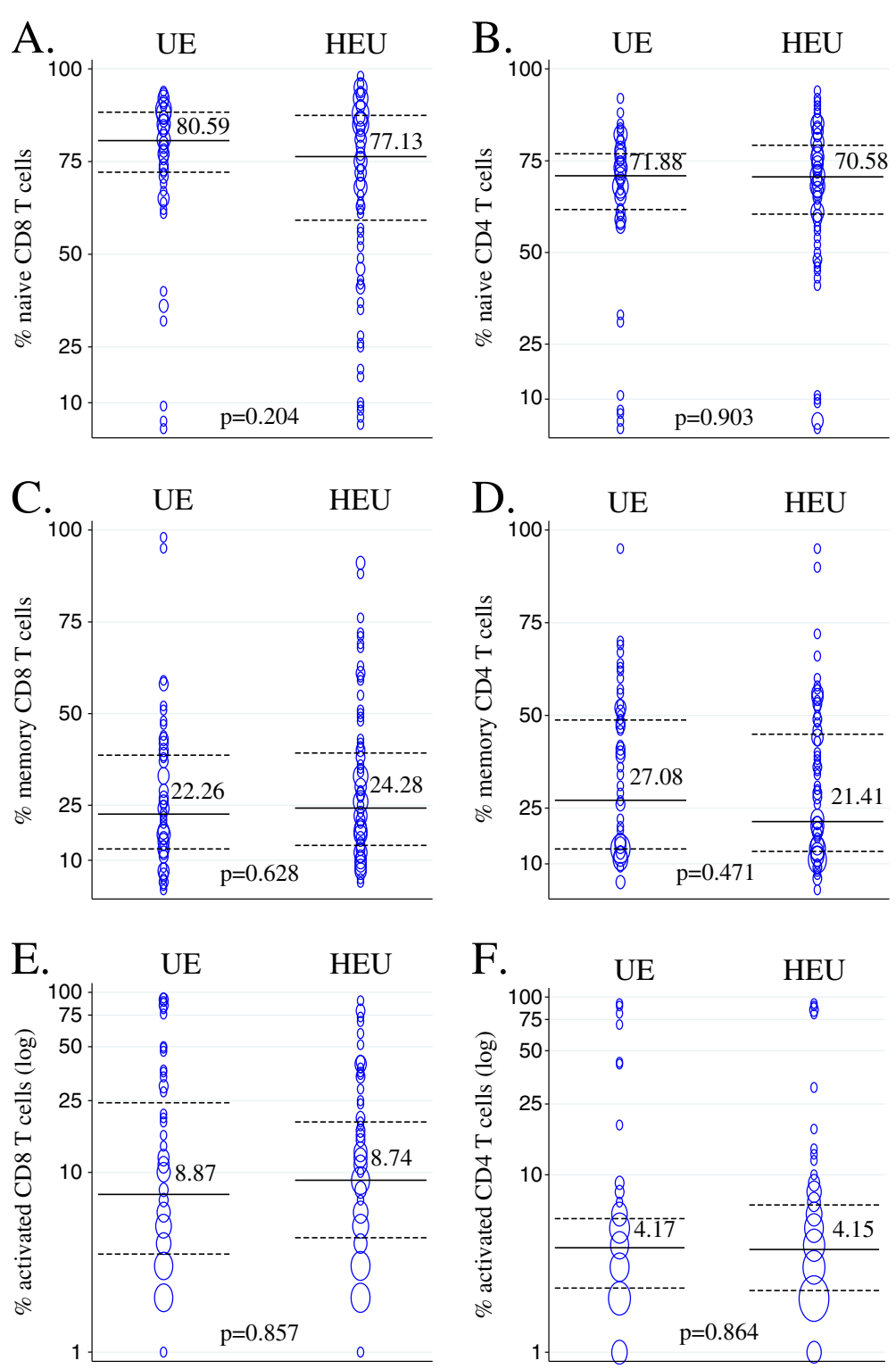

Figure 1 Distribution of T-cell populations among HIV-exposed infected (HEU) and unexposed (UE) infants at 1 month of age. Medians for data from HEU $(n=74)$ and UE $(n=56)$ are indicated and plotted in solid lines with dotted lines representing interquartile ranges. The size of bubbles is proportional to number of observations. A, C, and $\mathbf{E}$ show naïve, memory and activated CD8 T-cell populations and B, D and $\mathbf{F}$ show naïve, memory and activated CD4 T-cell populations. 


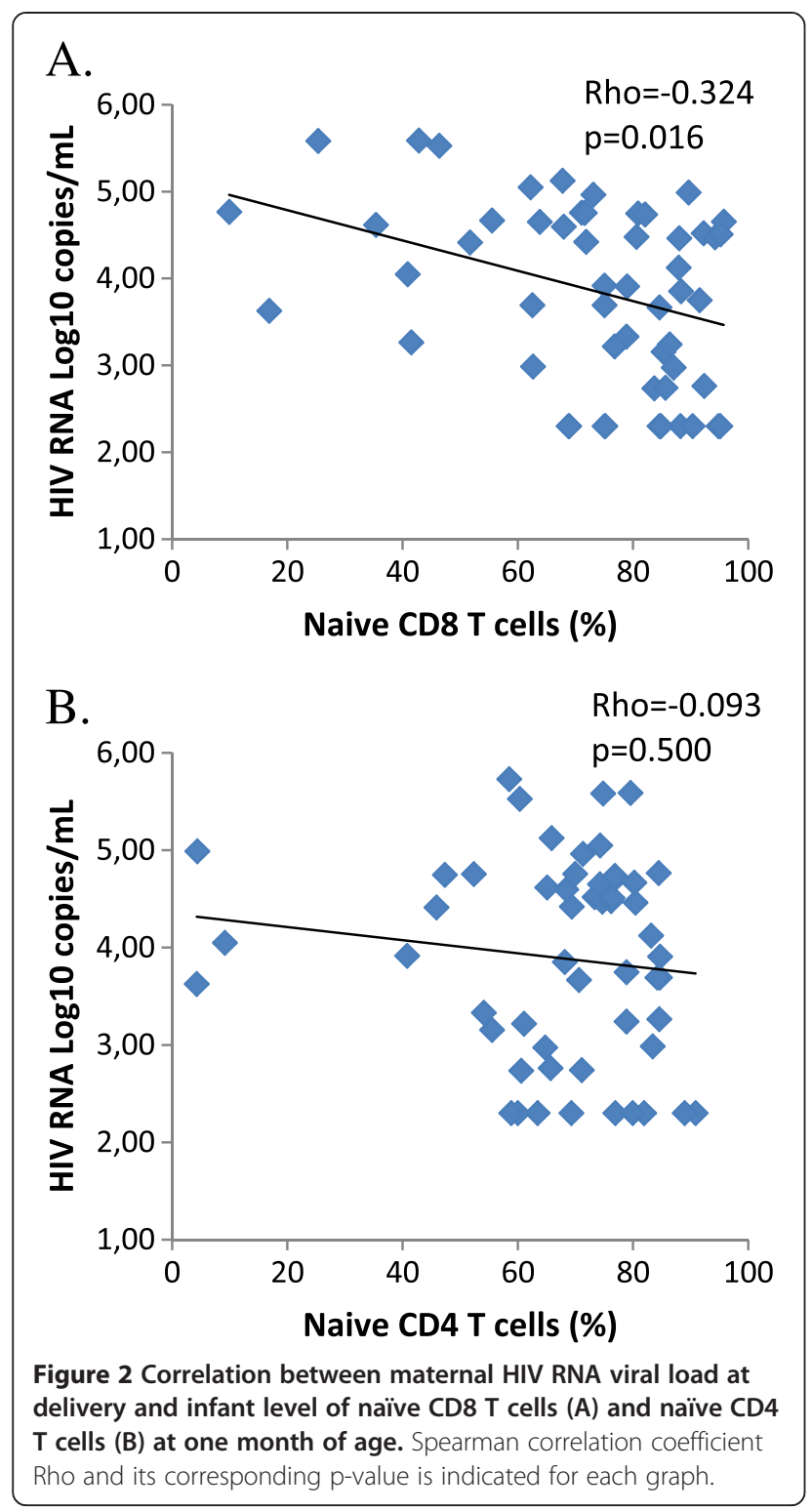

Spearman rho $=0.312 \mathrm{p}=0.02$ ). Percentage of activated and memory CD4 T-cells were not significantly associated with maternal HIV RNA viral load ( $\mathrm{p}=0.180, \mathrm{p}=0.733$ respectively).

When HEU infants were categorized according to their mothers HIV RNA at delivery, HEU infants born to women with HIV viral load above $5 \log _{10}$ copies $/ \mathrm{mL}$ had significantly lower levels of naïve CD8 T-cells and higher levels of memory CD8 T-cells at 1 month of age as compared to infants born to women with HIV RNA level below $5 \log _{10}$ copies/mL (Table 2). Maternal HIV RNA above $5 \log _{10}$ copies/mL was also associated with increased levels of activated CD8 T-cells although this did not reach significance. There were no associations between maternal HIV RNA loads and levels of infant naïve, activated or memory CD4 T-cells (Table 2). The
Table 2 Levels of T-cell populations in HIV exposed uninfected infants at 1 month of age according to maternal HIV RNA viral load at delivery

\begin{tabular}{|c|c|c|c|}
\hline $\begin{array}{l}\text { Cell } \\
\text { population }\end{array}$ & $\begin{array}{l}\text { HIV RNA } \geq 5 \log _{10} \\
(n=6) \\
{[\text { median (IQR)] }}\end{array}$ & $\begin{array}{l}\text { HIV RNA }<5 \log _{10} \\
(n=57) \\
{[\text { median (IQR)] }}\end{array}$ & p-value* \\
\hline \multicolumn{4}{|l|}{ CD8 T-cells } \\
\hline counts (cells/ $/$ l) & 1585 (1080-1702) & $1112(71-1447)$ & 0.14 \\
\hline activated (\%) & $25.8(11.2-40.3)$ & $8.8(3.3-18.3)$ & 0.09 \\
\hline naive (\%) & $54.3(42.8-67.8)$ & $79.8(67.6-88.2)$ & 0.04 \\
\hline memory (\%) & $54.6(30.5-75.8)$ & $21.9(14.3-40.3)$ & 0.014 \\
\hline \multicolumn{4}{|l|}{ CD4 T-cells } \\
\hline counts (cells/ $\mu l)$ & $2594(2174-3185)$ & $2291(1955-3028)$ & 0.337 \\
\hline activated (\%) & $5.3(4.0-7.8)$ & $3.5(2.1-6.5)$ & 0.557 \\
\hline naive (\%) & $70.1(60.4-74.8)$ & $70.3(60.6-78.9)$ & 0.79 \\
\hline memory (\%) & $19.8(15.4-21.7)$ & $23.9(13.2-45.8)$ & 0.574 \\
\hline
\end{tabular}

Analysis is based on $n=63$ infants with maternal HIV RNA measures available. *P-value from kruskal-wallis test.

infants born to women with high HIV RNA levels remained HIV-uninfected at subsequent visits although two were lost to follow up at the 12 month visit within the prospective observational study.

Higher maternal CD4 counts at delivery were significantly associated with higher level of infant naive CD4 T-cells (spearman correlation: rho $=0.365 \mathrm{p}=0.0018$ ) but not with naïve CD8 T-cells (spearman correlation: rho $=0.007 \mathrm{p}=0.95)$ nor with memory $\mathrm{CD} 4$ or $\mathrm{CD} 8$ T-cells $(\mathrm{p}=0.104$ and $\mathrm{p}=0.811$ respectively).

\section{Discussion}

In this study, at one month of age, HEU and unexposed infants had comparable median percentages of naïve, memory and activated CD4 T-cells and CD8 T-cells. However, within the HEU infant group, HEU born to women with high maternal HIV RNA level at delivery showed skewed naïve and activated CD8 T-cell populations at one month of age as compared to HEU infants born to women with lower viral load. In addition, maternal CD4 counts at delivery were positively associated with levels of infant naïve CD4 T-cells.

A naïve immune system with little previous antigen stimulation is expected to have high levels of naïve T-cells and low activation. With age, the levels of naïve cells decrease and memory cells increase reflecting antigen exposure [45,46]. HIV-infected infants show an activated phenotype whereby they display a decrease in naïve CD4 and/or CD8 T-cells and an increase in activated and memory T-cells [47]. Some studies have suggested that HEU infants also have naïve/memory T-cell skewing, albeit to a lesser extent, whereas other studies have not observed this skewing in HEU $[11,13-15,19]$. In the current study, differences in naïve/ 
memory T-cell skewing were not observed at one month of age between HEU and UE. However, significantly lower median \%CD4 T-cells and higher \%CD8 T-cells were observed in these HEU as compared to UE [20]. The inconsistency in the literature regarding naïve/ memory T-cell skewing in HEU infants leads to speculation as to the impact of factors such as time point of measurement, comparability of birth outcomes between HEU and UE infants, overall disease burden and maternal viral load. Studies of thymic naïve T-cell output in HEU infants by Nielsen et al., [14] found birth outcomes such as gestational age, birth weight and mode of delivery to impact observed infant naïve $\mathrm{T}$ cell levels. This could lead to confounding when assessing lymphocyte subset differences between HEU and UE which have very different birth outcomes. Additionally, time points for assessment of lymphocyte subsets have ranged from birth to adolescence, thus contributing to non-comparability of results. In our cohort, the birth weight, mode of delivery and feeding was not significantly different between HEU and unexposed infants. Since those infants requiring urgent care at birth were not included in our study, the absence of naïve/memory lymphocyte skewing in HEU at one month of age could be due to exclusion of those infants with poor birth outcomes. Alternatively, Manhiça is an endemic region of $P$. falciparum malaria and thus heightened malaria-induced immune activation in newborns could have masked differences due to HIV exposure. Our results showing correlation between maternal HIV viral load and infant CD8 T cell skewing suggest that only a sub population of HEU show T-cell skewing.

This study is one of the first to our knowledge to describe a relationship between maternal HIV RNA level and naïve/memory skewing in CD8 T-cell populations in HEU infants. This complements a recent study from Canada which showed that high maternal viral load was associated with higher levels of CD19+ B-cells in HEU infants [48]. Both studies point to a dose-dependent association of maternal HIV RNA level with lymphocyte subset skewing. In most cohorts studied in resource-rich countries, HIV viral load is undetectable or low due to effective pMTCT-HIV. In the current study, despite the existence of a pMTCT-HIV program, nearly $80 \%$ of women had detectable viral load at delivery. Among the HEU infants, linear associations were observed between levels of maternal HIV RNA viral load at delivery and naïve, pan-memory and activated CD8 T-cells. Maternal HIV viral load greater than $5 \log _{10}$ copies/mL was associated with a significantly lower percentage of naïve CD8 T-cells and a higher percentage of memory CD8 T-cells as compared to HEU infants born to mothers with maternal HIV RNA below $5 \log _{10}$ copies $/ \mathrm{mL}$. In utero infant exposure to maternal HIV particles and/or proteins could lead to lymphocyte subset skewing but may require a certain threshold or duration of maternal HIV exposure to be observed. The existence of such a threshold may help to explain inconsistent results in HEU immune abnormalities across studies. Additionally, in breastfeeding populations, the infant is potentially continuously exposed to HIV through breastmilk which would be higher in those women with higher plasma HIV RNA levels.

The main study limitations are the small sample size, particularly in the high maternal HIV RNA group, and the lack of evaluation of the duration of the T-cell skewing. Further studies including monitoring breast milk viral load exposure will be necessary. The analysis of memory T-cells was performed using the CD45RO marker, which is a non-specific marker of mature phenotype T-cells and does not distinguish between central and effector memory. The use of CD45RO may have underestimated levels of memory cells by excluding stem cell memory cells which are CD45RO [49] but this would have affected both HEU and UE groups. Other more specific markers that require greater than 4-color flow cytometry could not be assessed in Manhiça.

\section{Conclusions}

In conclusion, HEU infants born to women with high maternal HIV RNA level at delivery had skewed naïve and activated CD8 T-cell populations at one month of age. Improving pMTCT-HIV programs such that more women have undetectable viral load is crucial to decrease vertical transmission of HIV, but may also be important to reduce the consequences of HIV virus exposure in HEU infants. The current recommendation of HAART for all HIVinfected pregnant women (the $\mathrm{B}+$ option) is promising and will serve to reduce infant HIV exposure in SubSaharan Africa [50]. However, there will be a lag time until infant HIV exposure is eliminated in the region, thus elucidation of the clinical relevance of infant's exposure to maternal HIV [20,51-53] and its impact on altered T-cell populations should remain a priority.

\section{Abbreviations}

AZT: Zidovudine; HAART: Highly active antiretroviral therapy; HEU: HIVexposed uninfected; MTCT: Mother to child transmission; NVP: Nevirapine; pMTCT-HIV: Prevention of MTCT of HIV; WHO: World Health Organization.

\section{Competing interests}

The authors declare that they have no competing interests.

\section{Authors' contributions}

CMo, CSB, MR, CM, and DN contributed to conception and design of the study; ND, CMo, CSB, MR, CM and DN contributed to acquisition of data; ND, $\mathrm{CMo}$ and DN analysed the data; all authors contributed to interpretation of data; ND, CMo and DN drafted the article; All authors read, revised the article critically for important intellectual content, and gave final approval of the version to be published.

\section{Acknowledgments}

The authors are grateful to all the participants in the study and their infants, also to the dedicated staff of the Manhiça District Hospital, as well as field, 
clinic and data management staff at the Centro de Investigaçaõ em Saúde de Manhiça, Mozambique. The authors are particularly grateful to Jorcelina Rungo, Madalena Almeida, Marta Macamo, Luisa Agostinho, Lucas Nhatumbo, Nelito Ernesto José, Bendita Zavale, and Arnaldo Nhabunga for their contribution to patient visits, follow-up, laboratory tests and data management. The authors thank Llorenç Quinto for guidance in the statistical analysis.

Funding: This work was supported by the Spanish Ministry of Health [grant number PI070233]. The Manhiça Health Research Centre (CISM) receives core funding from the Spanish Agency for International Cooperation (AECID) and the HIV day hospital from the Agencia Catalana de Cooperació al Desenvolupament (ACCD). C.S. has received a grant from Spanish Ministry of Health [grant number P1070233]. For the remaining authors none were declared. The funders had no role in study design, data collection and analysis, decision to publish, or preparation of the manuscript.

\section{Author details}

${ }^{1}$ National Institute of Health, Maputo, Mozambique. ${ }^{2}$ Manhiça Health Research Centre (CISM), Manhiça, Mozambique. ${ }^{3}$ Barcelona Centre for International Health Research (CRESIB), Hospital Clinic, Universitat de Barcelona, C/Rossello 132, 4 , Barcelona, Spain.

\section{Received: 12 August 2014 Accepted: 15 January 2015} Published online: 03 February 2015

\section{References}

1. Kourtis AP, Lee FK, Abrams EJ, Jamieson DJ, Bulterys M. Mother-to-child transmission of HIV-1: timing and implications for prevention. Lancet Infect Dis. 2006;6(11):726-32.

2. Kind C, Rudin C, Siegrist CA, Wyler CA, Biedermann K, Lauper U, et al. Prevention of vertical HIV transmission: additive protective effect of elective Cesarean section and zidovudine prophylaxis. Swiss Neonatal HIV Study Group. Aids. 1998;12(2):205-10.

3. Mandelbrot L, Landreau-Mascaro A, Rekacewicz C, Berrebi A, Benifla JL, Burgard $M$, et al. Lamivudine-zidovudine combination for prevention of maternal-infant transmission of HIV-1. JAMA. 2001;285(16):2083-93.

4. European Collaborative Study. Mother-to-child transmission of HIV infection in the era of highly active antiretroviral therapy. Clin Infect Dis. 2005;40(3):458-65.

5. Abdool Karim Q, Kharsany AB, Frohlich JA, Werner L, Mashego M, Mlotshwa $M$, et al. Stabilizing HIV prevalence masks high HIV incidence rates amongst rural and urban women in KwaZulu-Natal, South Africa. Int J Epidemiol. 2010;2010:3.

6. Gonzalez R, Munguambe K, Aponte J, Bavo C, Nhalungo D, Macete E, et al. High HIV prevalence in a southern semi-rural area of Mozambique: a community-based survey. HIV Med. 2012;13(10):581-8.

7. Filteau S. The HIV-exposed, uninfected African child. Trop Med Int Health. 2009;14(3):276-87.

8. Bunders M, Thorne C, Newell ML. Maternal and infant factors and lymphocyte, CD4 and CD8 cell counts in uninfected children of HIV-1-infected mothers. Aids. 2005;19(10):1071-9.

9. Rich KC, Brambilla D, Pitt J, Moye J, Cooper E, Hillyer G, et al. Lymphocyte phenotyping in infants: maturation of lymphocyte subpopulations and the effects of HIV infection. Clin Immunol Immunopathol. 1997;85(3):273-81.

10. Borges-Almeida E, Milanez HM, Vilela MM, Cunha FG, Abramczuk BM, Reis-Alves SC, et al. The impact of maternal HIV infection on cord blood lymphocyte subsets and cytokine profile in exposed non-infected newborns. BMC Infect Dis. 2011;11:38.

11. Clerici M, Saresella M, Colombo F, Fossati S, Sala N, Bricalli D, et al. T-lymphocyte maturation abnormalities in uninfected newborns and children with vertical exposure to HIV. Blood. 2000;96(12):3866-71.

12. Kuhn L, Kasonde P, Sinkala M, Kankasa C, Semrau K, Scott N, et al. Does severity of HIV disease in HIV-infected mothers affect mortality and morbidity among their uninfected infants? Clin Infect Dis. 2005:41(11):1654-61. Epub 2005 Oct 1627.

13. Miyamoto M, Pessoa SD, Ono E, Machado DM, Salomao R, Succi RC, et al. Low CD4+ T-cell levels and B-cell apoptosis in vertically HIV-exposed noninfected children and adolescents. J Trop Pediatr. 2010;56(6):427-32.

14. Nielsen SD, Jeppesen DL, Kolte L, Clark DR, Sorensen TU, Dreves AM, et al. Impaired progenitor cell function in HIV-negative infants of HIV-positive mothers results in decreased thymic output and low CD4 counts. Blood. 2001;98(2):398-404.

15. Ono E, Nunes dos Santos AM, de Menezes Succi RC, Machado DM, de Angelis DS, Salomao R, et al. Imbalance of naive and memory $T$ lymphocytes with sustained high cellular activation during the first year of life from uninfected children born to HIV-1-infected mothers on HAART. Braz J Med Biol Res. 2008;41(8):700-8.

16. Pahwa S, Read JS, Yin W, Matthews Y, Shearer W, Diaz C, et al. CD4+/CD8+ T cell ratio for diagnosis of HIV-1 infection in infants: Women and Infants Transmission Study. Pediatrics. 2008;122(2):331-9.

17. Embree J, Bwayo J, Nagelkerke N, Njenga S, Nyange P, Ndinya-Achola J, et al. Lymphocyte subsets in human immunodeficiency virus type 1-infected and uninfected children in Nairobi. Pediatr Infect Dis J. 2001;20(4):397-403.

18. Kupka R, Msamanga Gl, Aboud S, Manji KP, Duggan C, Fawzi WW. Patterns and predictors of CD4 T-cell counts among children born to HIV-infected women in Tanzania. J Trop Pediatr. 2009;55(5):290-6.

19. Mansoor N, Abel B, Scriba TJ, Hughes J, de Kock M, Tameris M, et al. Significantly skewed memory CD8+ T cell subsets in HIV-1 infected infants during the first year of life. Clin Immunol. 2009;130(3):280-9.

20. Moraleda C, de Deus N, Serna-Bolea C, Renom M, Quinto L, Macete E, et al. Impact of HIV Exposure on Health Outcomes in HIV-Negative Infants Born to HIV-Positive Mothers in Sub-Saharan Africa. J Acquir Immune Defic Syndr. 2014;65(2):182-9.

21. Schramm DB, Kuhn L, Gray GE, Tiemessen CT. In vivo effects of HIV-1 exposure in the presence and absence of single-dose nevirapine on cellular plasma activation markers of infants born to HIV-1-seropositive mothers. J Acquir Immune Defic Syndr. 2006;42(5):545-53.

22. Kasahara TM, Hygino J, Blanco B, Xavier L, Araujo-Lima CF, Guillermo LV, et al. The impact of maternal anti-retroviral therapy on cytokine profile in the uninfected neonates. Hum Immunol. 2013;74(9):1051-6.

23. Reikie BA, Adams RC, Leligdowicz A, Ho K, Naidoo S, Ruck CE, et al. Altered innate immune development in HIV-exposed uninfected infants. J Acquir Immune Defic Syndr. 2014;66(3):245-55.

24. Slyker JA, Lohman-Payne B, John-Stewart GC, Dong T, Mbori-Ngacha D, Tapia K, et al. The impact of HIV-1 infection and exposure on natural killer (NK) cell phenotype in Kenyan infants during the first year of life. Frontiers Immunol. 2012;3:399.

25. Kolte L, Rosenfeldt V, Vang L, Jeppesen D, Karlsson I, Ryder LP, et al. Reduced thymic size but no evidence of impaired thymic function in uninfected children born to human immunodeficiency virus-infected mothers. Pediatr Infect Dis J. 2011;30(4):325-30.

26. Le Chenadec J, Mayaux MJ, Guihenneuc-Jouyaux C, Blanche S. Perinatal antiretroviral treatment and hematopoiesis in HIV-uninfected infants. Aids. 2003;17(14):2053-61.

27. Bunders M, Lugada E, Mermin J, Downing R, Were W, Thorne C, et al. Within and between race differences in lymphocyte, CD4+, CD8+ and neutrophil levels in HIV-uninfected children with or without HIV exposure in Europe and Uganda. Ann Trop Paediatr. 2006;26(3):169-79.

28. Eggena MP, Barugahare B, Okello M, Mutyala S, Jones N, Ma Y, et al. $T$ cell activation in HIV-seropositive Ugandans: differential associations with viral load, CD4+ T cell depletion, and coinfection. J Infect Dis. 2005;191(5):694-701. Epub 2005 Jan 2031.

29. Kassu A, Tsegaye A, Petros B, Wolday D, Hailu E, Tilahun T, et al. Distribution of lymphocyte subsets in healthy human immunodeficiency virus-negative adult Ethiopians from two geographic locales. Clin Diagn Lab Immunol. 2001;8(6):1171-6.

30. Messele T, Abdulkadir M, Fontanet AL, Petros B, Hamann D, Koot M, et al. Reduced naive and increased activated CD4 and CD8 cells in healthy adult Ethiopians compared with their Dutch counterparts. Clin Exp Immunol. 1999;115(3):443-50.

31. Rizzardini G, Trabattoni D, Saresella M, Piconi S, Lukwiya M, Declich S, et al. Immune activation in HIV-infected African individuals. Italian-Ugandan AIDS cooperation program. Aids. 1998;12(18):2387-96.

32. Steiner K, Myrie L, Malhotra I, Mungai P, Muchiri E, Dent A, et al. Fetal immune activation to malaria antigens enhances susceptibility to in vitro HIV infection in cord blood mononuclear cells. J Infect Dis. 2010;202(6):899-907.

33. Ismaili J, van der Sande M, Holland MJ, Sambou I, Keita S, Allsopp C, et al. Plasmodium falciparum infection of the placenta affects newborn immune responses. Clin Exp Immunol. 2003;133(3):414-21. 
34. Mazzola TN, da Silva MT, Abramczuk BM, Moreno YM, Lima SC, Zorzeto TQ, et al. Impaired Bacillus Calmette-Guerin cellular immune response in HIV-exposed, uninfected infants. Aids. 2011;25(17):2079-87.

35. Kidzeru EB, Hesseling AC, Passmore JA, Myer L, Gamieldien H, Tchakoute CT, et al. In-utero exposure to maternal HIV infection alters T-cell immune responses to vaccination in HIV-uninfected infants. Aids. 2014;28(10):1421-30.

36. Venkatesh KK, de Bruyn G, Marinda E, Otwombe K, van Niekerk R, Urban M, et al. Morbidity and mortality among infants born to HIV-infected women in South Africa: implications for child health in resource-limited settings. J Trop Pediatr. 2011;57(2):109-19.

37. Marston M, Zaba B, Salomon JA, Brahmbhatt $H$, Bagenda D. Estimating the net effect of HIV on child mortality in African populations affected by generalized HIV epidemics. J Acquir Immune Defic Syndr. 2005;38(2):219-27.

38. Newell ML, Coovadia H, Cortina-Borja M, Rollins N, Gaillard P, Dabis F. Mortality of infected and uninfected infants born to HIV-infected mothers in Africa: a pooled analysis. Lancet. 2004;364(9441):1236-43.

39. Marinda E, Humphrey JH, lliff PJ, Mutasa K, Nathoo KJ, Piwoz EG, et al. Child mortality according to maternal and infant HIV status in Zimbabwe. Pediatr Infect Dis J. 2007;26(6):519-26.

40. Heresi GP, Caceres E, Atkins JT, Reuben J, Doyle M. Pneumocystis carinii pneumonia in infants who were exposed to human immunodeficiency virus but were not infected: an exception to the AIDS surveillance case definition. Clin Infect Dis. 1997;25(3):739-40.

41. Otieno RO, Ouma C, Ong'echa JM, Keller CC, Were T, Waindi EN, et al. Increased severe anemia in HIV-1-exposed and HIV-1-positive infants and children during acute malaria. AIDS. 2006;20(2):275-80.

42. Thea DM, St Louis ME, Atido U, Kanjinga K, Kembo B, Matondo M, et al. A prospective study of diarrhea and HIV-1 infection among 429 Zairian infants. N Engl J Med. 1993;329(23):1696-702.

43. McNally LM, Jeena PM, Gajee K, Thula SA, Sturm AW, Cassol S, et al. Effect of age, polymicrobial disease, and maternal HIV status on treatment response and cause of severe pneumonia in South African children: a prospective descriptive study. Lancet. 2007:369(9571):1440-51.

44. Antiretroviral drugs for treating pregnant women and preventing HIV infection in infants: towards universal access. Recommendations for a public health approach. [http://www.who.int/hiv/pub/mtct/guidelines/en/]

45. de Vries E, de Bruin-Versteeg S, Comans-Bitter WM, van Dongen JJ, de Groot R, Boerma GJ, et al. Longitudinal follow-up of blood lymphocyte subpopulations from birth to 1 year of age. J Pediatr. 1998;133(4):586-8.

46. Tsegaye A, Wolday D, Otto S, Petros B, Assefa T, Alebachew T, et al. Immunophenotyping of blood lymphocytes at birth, during childhood, and during adulthood in HIV-1-uninfected Ethiopians. Clin Immunol. 2003;109(3):338-46.

47. Rabin RL, Roederer M, Maldonado Y, Petru A, Herzenberg LA. Altered representation of naive and memory CD8 T cell subsets in HIV-infected children. J Clin Invest. 1995;95(5):2054-60.

48. Kakkar F, Lamarre V, Ducruet T, Boucher M, Valois S, Soudeyns $H$, et al. Impact of maternal HIV-1 viremia on lymphocyte subsets among HIV-exposed uninfected infants: protective mechanism or immunodeficiency. BMC Infect Dis. 2014;14:236.

49. Farber DL, Yudanin NA, Restifo NP. Human memory T cells: generation, compartmentalization and homeostasis. Nat Rev Immunol. 2014;14(1):24-35.

50. WHO: Consolidated Guidelines on the use of Antiretroviral drugs for treating and preventing HIV infection; recommendations for a public health approach. Geneva: 2013.

51. Sugandhi N, Rodrigues J, Kim M, Ahmed S, Amzel A, Tolle M, et al. Child Survival Working Group of the Interagency Task Team on the P et al. HIV-exposed infants: rethinking care for a lifelong condition. Aids. 2013;27 Suppl 2:S187-95.

52. Kourtis AP, Wiener J, Kayira D, Chasela C, Ellington SR, Hyde L, et al. Health outcomes of HIV-exposed uninfected African infants. Aids. 2013;27(5):749-59.

53. Rollins NC, Ndirangu J, Bland RM, Coutsoudis A, Coovadia HM, Newell ML. Exclusive Breastfeeding, Diarrhoeal Morbidity and All-Cause Mortality in Infants of HIV-Infected and HIV Uninfected Mothers: An Intervention Cohort Study in KwaZulu Natal, South Africa. PLoS One. 2013;8(12):e81307.

\section{Submit your next manuscript to BioMed Central and take full advantage of:}

- Convenient online submission

- Thorough peer review

- No space constraints or color figure charges

- Immediate publication on acceptance

- Inclusion in PubMed, CAS, Scopus and Google Scholar

- Research which is freely available for redistribution

Submit your manuscript at www.biomedcentral.com/submit 